\title{
Combined prognostic value of the SUVmax derived from FDG-PET and the lymphocyte- monocyte ratio in patients with stage IIIB-IV non-small cell lung cancer receiving chemotherapy
}

Kewei Zhao ${ }^{1 \dagger}$, Chunsheng Wang ${ }^{1 \dagger}$, Fang Shi ${ }^{2}$, Yong Huang ${ }^{3}$, Li Ma ${ }^{3}$, Minghuan $\mathrm{Li}^{2}$ and Yipeng Song ${ }^{1 *}$

\begin{abstract}
Background: We evaluated the prognostic potential of tumor ${ }^{18}$ F-fluorodeoxyglucose (FDG) uptake derived from positron emission tomography (PET) and known inflammatory hematological markers, both individually and in combination, for chemosensitivity and survival in patients with stage IIIB-IV non-small cell lung cancer (NSCLC) receiving first-line chemotherapy.

Methods: A total of 149 patients with stage IIIB and IV NSCLC (based on TNM 7th edition) were retrospectively reviewed. Maximum standardized uptake value (SUVmax) were used to quantitatively assess FDG uptake. The lymphocyte-monocyte ratio (LMR), neutrophil-lymphocyte ratio (NLR) and platelet-lymphocyte ratio (PLR) were selected as hematological markers. Receiver operating characteristic (ROC) curves were constructed for the determination of optimal cut-off values to predict chemotherapeutic response.
\end{abstract}

Results: Patients with SUVmax $>11.6$ or LMR $\leq 3.73$ exhibited a significantly lower objective response rate (ORR) to chemotherapy $(p<0.001$ and $p<0.001)$. Through multivariable logistic regression analysis, both the SUVmax and LMR were identified as independent predictive factors for chemotherapeutic response ( $p=0.001$ and $p<0.001$ ). Furthermore, a multivariable Cox proportional hazard model identified a high SUVmax (> 11.6) and low LMR $(\leq 3.73)$ as independent predictors of poor PFS $(p<0.001$ and $p=0.025)$ and OS $(p<0.001$ and $p=0.032)$. A novel score system was constructed based on the SUVmax and LMR (SUV_LMR score), and patients were stratified into three subgroups. The patients with a score of 0 had a significantly higher ORR (88.9\%) than did those with a score of 1 $(59.6 \%)$ and score of $2(25.0 \%)(p<0.001)$. Moreover, multivariable Cox analysis further identified the SUV_LMR score as an independent prognostic factor for PFS $(p<0.001)$ and OS $(p<0.001)$.

(Continued on next page)

\footnotetext{
* Correspondence: songypyhd@sina.com

†Kewei Zhao and Chunsheng Wang contributed equally to this work. 'Department of Radiation Oncology, Yantai Yuhuangding Hospital, 20 Yudong Road, Yantai 264000, Shandong, People's Republic of China Full list of author information is available at the end of the article
}

C C The Author(s). 2021 Open Access This article is licensed under a Creative Commons Attribution 4.0 International License, which permits use, sharing, adaptation, distribution and reproduction in any medium or format, as long as you give appropriate credit to the original author(s) and the source, provide a link to the Creative Commons licence, and indicate if changes were made. The images or other third party material in this article are included in the article's Creative Commons licence, unless indicated otherwise in a credit line to the material. If material is not included in the article's Creative Commons licence and your intended use is not permitted by statutory regulation or exceeds the permitted use, you will need to obtain permission directly from the copyright holder. To view a copy of this licence, visit http://creativecommons.org/licenses/by/4.0/. The Creative Commons Public Domain Dedication waiver (http://creativecommons.org/publicdomain/zero/1.0/) applies to the data made available in this article, unless otherwise stated in a credit line to the data. 
(Continued from previous page)

Conclusions: Pre-treatment SUVmax and LMR were not only predictive factors for chemotherapeutic response but also independent prognostic factors of survival in stage IIIB-IV NSCLC. Moreover, the SUV_LMR score, which is based on primary tumor metabolic activity and the systemic inflammatory response, might provide a promising tool to predict chemosensitivity, recurrence and survival of advanced NSCLC.

Keywords: Non-small cell lung cancer, Maximum standardized uptake value, Lymphocyte-monocyte ratio, Response, Survival

\section{Background}

Globally, lung cancer has 5-year survival rates as low as $15 \%$ [1]. Non-small cell lung cancer (NSCLC) is the most common pathological type of lung cancer, accounting for $85 \%$ of all cases [1]. Owing to lack of early symptoms, close to $70 \%$ of patients are already in late stage when they are initially diagnosed with NSCLC, and most of them have lost the opportunity for surgical therapy [2]. For advanced stage IIIB and IV NSCLC, the front line therapy remains platinum-based doublet chemotherapy [3]. However, the response rate to chemotherapy and the survival in advanced NSCLC are not ideal [4]. In order to develop appropriate treatment guidelines and balance therapeutic toxicity in individual patients, precise prediction of chemotherapy sensitivity and prognosis is crucial. The anatomical range of the tumor, which is expressed by the tumor, node, metastasis (TNM) classification, is recognized as the most powerful prognostic factor for lung cancer [5]. However, TNM staging is only an anatomical description of the tumor and is not enough to develop treatment programs and evaluate prognosis. In the future, the most promising will be the composite prognostic model for NSCLC based on biological characteristics in conjunction TNM staging [6].

Reprogramming energy metabolism is one of the biological hallmarks in cancer [7]. Indeed, significantly elevated glucose uptake and utilization have been observed in various types of tumors [7]. ${ }^{18}$ F-fluorodeoxyglucose positron emission tomography/computed tomography $\left({ }^{18}\right.$ F-FDG PET/CT), which can noninvasively quantify glucose uptake that precedes anatomic changes, has been widely applied in NSCLC diagnosis, staging, response evaluation and survival prediction [8]. Maximum standardized uptake value (SUVmax) is a commonly used parameter for quantifying FDG uptake and has been reported to have a strong prognostic value for NSCLC [9-13]. The common conclusion of these studies is that higher values of SUVmax could predict a high risk of disease recurrence or death. However, this conclusion is still controversial since some studies also demonstrated that SUVmax cannot provide reliable prognostic information for NSCLC patients [14, 15]. Therefore, the prognostic role of SUVmax in NSCLC needs further validation.
Tumor-promoting inflammation is another recognized biological hallmark of cancer [7]. Accumulating evidence has demonstrated that the cancer-related inflammation response can enhance tumor progression by facilitating angiogenesis, invasion, and metastasis [16-18]. Hematological markers of systemic inflammation include the lymphocyte-monocyte ratio (LMR), neutrophillymphocyte ratio (NLR) and platelet-lymphocyte ratio (PLR), all of which are prognostic markers for a range of solid tumors, including NSCLC [19-26]. However, the optimal hematological markers for predicting clinical outcomes in NSCLC have yet to be defined [22-26].

The combined evaluation of FDG uptake of primary tumor and systemic inflammatory response may provide complementary information and may be highly effective at predicting outcomes in advanced NSCLC patients. Hence, we combined the two factors to explore their integrated predictive value for treatment response and survival in stage IIIB-IV NSCLC patients.

\section{Methods}

Patient selection

We reviewed the clinical data of patients pathologically diagnosed with NSCLC from September 2013 to June 2017. All enrolled patients received ${ }^{18}$ F-FDG PET/CT scanning within two weeks prior to treatment. According to the PET/CT and other imaging examinations, all patients were staged based on 7th TNM staging system. Patients were included according to: 1) age, 18-75 years; 2) clinical stage IIIB or IV; 3) Eastern Cooperative Oncology Group performance status (ECOG PS) 0-1; 4) no history of other malignancies; 5) without acute infections or autoimmune diseases; and 6) received $\geq 4$ cycles of first-line platinum-based doublet chemotherapy. Data regarding age, sex, ECOG PS, smoking history, lesion type, histological type, and clinical stage were extracted and analysed. All patients received first-line chemotherapy and additional radiotherapy if indicated.

\section{${ }^{18} \mathrm{~F}$-FDG PET/CT scanning and image analysis}

${ }^{18}$ F-FDG PET/CT was performed on an advanced PET/ CT scanner (Discovery LS, GE Healthcare). All of them with 6-h fasting and ensure blood glucose level was $<$ $200 \mathrm{ml} / \mathrm{dL}$ before receiving an average of $5.5 \mathrm{MBq} / \mathrm{kg}$ 
${ }^{18}$ F-FDG intravenous injections. One hour later, a whole-body PET and CT scans began, ranging from the base of the skull to the proximal thigh. After CT-derived attenuation correction, the PET images were reconstructed by the ordered subsets expectation maximization algorithm. The reconstruction layer thickness was 4.25 $\mathrm{mm}$ and the image matrix size were $128 \times 128$. The CT, PET and fused images were displayed on the Xeleris workstation (GE Healthcare). Two experienced diagnostic specialists reviewed the PET/CT images independently. FDG uptake was quantified using SUV, and the highest pixel value of SUV within region of interest (ROI) was defined as the SUVmax.

\section{Definition of hematological markers}

All patients underwent routine blood tests within one week before treatment. The peripheral counts of white blood cell (WBC), lymphocytes, neutrophils and platelets were recorded. The LMR was defined as the ratio of the lymphocyte count to the monocyte count. The NLR was calculated as the neutrophil count divided by the lymphocyte count, and the PLR was calculated as the platelet count divided by the lymphocyte count.

\section{Evaluation of response and follow-up}

After four weeks of treatment completion, tumor response was assessed based on the RECIST1.1. According to these criteria, responders were classified as complete response (CR) and partial response (PR), and nonresponders were classified as stable disease (SD) and progressive disease (PD). Objective response rates (ORRs) were calculated as the percentage of $C R$ and $P R$ among all treated patients.

The patients were followed up every 3 months for the first 2 years, every 6 months for the next 3 years, and every year after 5 years. Overall survival (OS) was calculated from the date of treatment initiation to the date of death or final follow-up. Progression-free survival (PFS) was calculated from the date of treatment initiation to the date of diagnosis of local recurrence/distant metastasis, or final follow-up. Medical records and telephone interviews were used to compile follow-up data of patients. The median follow-up was 16.1 months (range: 4.7-63.2 months). The last follow-up date was December 10, 2018.

\section{Statistical analysis}

Study data were analyzed on SPSS version 22.0 and MedCalc program version 18.11. Correlations between SUVmax and hematological markers were evaluated using Spearman's correlation coefficient tests. Receiveroperating characteristic (ROC) curves were constructed to obtain optimal cut-off values of SUVmax and hematological markers for identifying the treatment responders. Delong's tests were used to compare the area under the curves (AUCs) of the three hematological markers. The correlation of each variables and treatment response were assessed via logistic regression models. Kaplan-Meier (KM) curves and log-rank tests were used for the assessment of patient survival. Prognostic factors with $p<0.05$ in univariable analyses were entered into multivariable Cox proportional hazards model. All tests were two-sided and $\mathrm{p}<0.05$ was deemed statistically significant.

\section{Results}

\section{Patient data}

In total, 149 eligible patients were included into analysis. Among them, 111 (74.5\%) were male and 38 (25.5\%) were female, with a median age of 61 (range: 36-75) years. Regarding histological subtype, 55 (36.9\%) had squamous cell carcinoma, and 94 (63.1\%) were diagnosed as adenocarcinoma. Amongst them, 69 (46.3\%) were at stage IIIB, and $80(53.7 \%)$ were at stage IV. All included patients received 4-6 (median: 4) cycles of first-line platinum-based chemotherapy and the regimens including cisplatin/paclitaxel, cisplatin/docetaxel, cisplatin/gemcitabine or cisplatin/pemetrexed. Detailed baseline characteristics were listed in the Table 1 .

\section{Correlation between SUVmax and hematological markers}

From correlation analysis, LMR $(\mathrm{r}=-0.207, p=0.011)$ and NLR $(\mathrm{r}=0.229, p=0.005)$ showed significant yet quite weak correlations with SUVmax, while PLR did not $(\mathrm{r}=0.086, p=0.296)$ (Fig. 1).

\section{Analysis of ROC curves}

The AUC of SUVmax for identifying responders was 0.705 , with an optimal cut-off value of 11.6 (sensitivity $72.5 \%$, specificity $63.7 \%$ ) (Fig. 2). The AUC of LMR, NLR and PLR was 0.732, 0.615 and 0.566, respectively. According to the Delong's test, the AUC of LMR was higher than that of NLR $(\triangle \mathrm{AUC}=0.117, p=0.004)$ and of PLR $(\triangle \mathrm{AUC}=0.165, p=0.001)$. The optimal cut-off values of LMR, NLR, and PLR were 3.73 (sensitivity $60 \%$, specificity $82.6 \%$ ), 2.67 (sensitivity $65.2 \%$, specificity $56.2 \%$ ), and 164 (sensitivity $46.4 \%$, specificity $67.5 \%$ ), respectively (Fig. 2). Patients were divided into high and low groups based on these optimal cut-off values.

Univariable and multivariable analyses of tumor response Of the 149 NSCLC patients, CR, PR, SD and PD occurred in 3 (2.0\%), 77 (51.7\%), 61 (40.9\%) and 8 (5.4\%) cases, respectively. The overall ORR was $53.7 \%(80 / 149)$.

In univariable analyses, those with SUVmax values $\leq 11.6$ had a higher ORR than did those with SUVmax > $11.6(72.5 \%$ vs $37.5 \%, p<0.001)$, whereas those with LMR > 3.73 had a higher ORR than did those with 
Table 1 Baseline characteristics of 149 patients

\begin{tabular}{|c|c|c|}
\hline Characteristics & Number (\%) & Median (range) \\
\hline Age (years) & & $61(36-75)$ \\
\hline$\leq 65$ & 95 (63.8\%) & \\
\hline$>65$ & $54(36.2 \%)$ & \\
\hline \multicolumn{3}{|l|}{ Sex } \\
\hline Male & 111 (74.5\%) & \\
\hline Female & 38 (25.5\%) & \\
\hline \multicolumn{3}{|l|}{ Smoking } \\
\hline Never & $60(40.3 \%)$ & \\
\hline Ever & 89 (59.7\%) & \\
\hline \multicolumn{3}{|l|}{ ECOG PS } \\
\hline 0 & 73 (49.0\%) & \\
\hline 1 & 76 (51.0\%) & \\
\hline \multicolumn{3}{|l|}{ Histological type } \\
\hline Adenocarcinoma & 94 (63.1\%) & \\
\hline Squamous & 55 (36.9\%) & \\
\hline \multicolumn{3}{|l|}{ Lesion type } \\
\hline Central & 78 (52.3\%) & \\
\hline Peripheral & 71 (47.7\%) & \\
\hline \multicolumn{3}{|l|}{ Clinical stage } \\
\hline$\| \mathrm{II}$ & 69 (46.3\%) & \\
\hline IV & $80(53.7 \%)$ & \\
\hline \multicolumn{3}{|l|}{ CEA } \\
\hline Normal & 95 (63.8\%) & \\
\hline Increased & $54(36.2 \%)$ & \\
\hline \multicolumn{3}{|l|}{ Albumin } \\
\hline Decreased & $50(33.6 \%)$ & \\
\hline Normal & 99 (66.4\%) & \\
\hline WBC $\left(\times 10^{9} / \mathrm{L}\right)$ & & $7.6(3.6-12)$ \\
\hline LMR & & $3.25(0.98-12.5)$ \\
\hline NLR & & $2.78(1.05-8.14)$ \\
\hline PLR & & $143(35-352)$ \\
\hline SUVmax & & $11.8(3.3-28.5)$ \\
\hline
\end{tabular}

ECOG PS Eastern Cooperative Oncology Group Performance Status, CEA carcinoembryonic antigen, WBC white blood cell, $L M R$ lymphocyte-monocyte ratio, NLR neutrophil-lymphocyte ratio, PLR platelet-lymphocyte ratio, SUVmax maximum standardized uptake value

$\mathrm{LMR} \leq 3.73$ ( $80 \%$ vs $36 \%, p<0.001)$. In addition to high SUVmax and low LMR, old age $(p=0.042)$, high ECOG PS $(p=0.001)$, advanced clinical stage $(p=0.004)$, increased CEA level $(\mathrm{p}=0.042)$, high WBC $(p=0.003)$ and NLR $(p=0.009)$ were also associated with poor ORRs.

In multivariable analyses, the SUVmax (odds ratio [OR]: 0.217; 95\% confidence interval [CI]: 0.090-0.525; $\mathrm{p}=0.001$ ), LMR (OR: 0.167; 95\% CI: 0.062-0.454; $p<$ 0.001 ), and clinical stage (OR: 0.283; 95\% CI: $0.112-$
$0.718 ; p=0.008)$ were demonstrated as independent predictors of treatment response (Table 2).

\section{Univariable and multivariable analyses of PFS and OS}

KM curves analysis showed that patients with a high SUVmax (>11.6) exhibited significantly shorter PFS and OS than did those with low SUVmax (median PFS: 7.6 vs 13.4 months, $p<0.001$; median OS: 14.5 vs 22.5 months, $\mathrm{p}<0.001$ ) (Fig. 3a-b). Similarly, the PFS and OS of patients with low LMR $(\leq 3.73)$ were significantly lower than those with high LMR (median PFS: 7.1 vs 13.4 months, $p<0.001$; Median OS: 14.4 vs 21.9 months, $p<0.001$ ) (Fig. 3c-d).

In the univariable analysis, age (PFS, $p=0.015$; OS, $p=0.008$ ), ECOG PS (PFS, $p=0.007$; OS, $p=0.019$ ), clinical stage (PFS, $p=0.017$; OS, $p=0.045$ ), first-line response (PFS, $p<0.001$; OS, $p<0.001$ ), LMR (PFS, $p<$ 0.001 ; OS, $p<0.001$ ) and SUVmax (PFS, $p<0.001$; OS, $p<0.001)$ were significantly correlated with PFS and OS. Albumin level also correlated with PFS $(p=0.023)$ (Table 3).

In the multivariable analysis, the SUVmax was independently correlated with both PFS (hazard ratio [HR]: $2.110 ; 95 \% \mathrm{CI}: 1.400-3.179 ; \mathrm{p}<0.001)$ and OS (HR: 2.760 ; 95\%CI: $1.789-4.257 ; p<0.001$ ). Furthermore, LMR was also independently associated with PFS (HR: $1.602 ; 95 \% \mathrm{CI}: 1.060-2.420 ; p=0.025$ ) and OS (HR: $1.621 ; 95 \%$ CI: $1.042-2.521 ; p=0.032$ ). Other independent prognostic factors for PFS and OS included clinical stage (PFS, $p=0.003$; OS, $p=0.002$ ) and first-line response (PFS, $p=0.037$; OS, $p=0.011$ ) (Table 4, Model 1).

\section{The value of the LMR_SUV score in predicting treatment response and survival}

To further discriminate patients with different outcomes, a novel scoring system termed the SUV_LMR score that includes SUVmax and LMR was constructed. The score was categorized as follows: score 0 , patients with low SUVmax $(\leq 11.6)$ and high LMR (>3.73); score 2, patients with high SUVmax (>11.6) and low LMR ( $\leq 3.73)$; and score 1 , all remaining patients.

First, we evaluated the differences in treatment response among the three subgroups. The patients with a score of 0 had the highest ORR of $88.9 \%$, whereas patients with a score of 2 had the lowest ORR of only $25 \%$. In addition, the ORR of patients with a score of 1 was intermediate, at $59.6 \%$. More importantly, significant inter-group differences in the ORRs were observed ( 0 vs $1, p=0.002,1$ vs $2, p<0.001$; and 0 vs $2, p<0.001$ ) (Table 5).

Moreover, we examined the prognostic value of the SUV_LMR score. The median PFS for patients with scores of 0,1 , and 2 was 16.1, 11.1, and 5.8 months, 

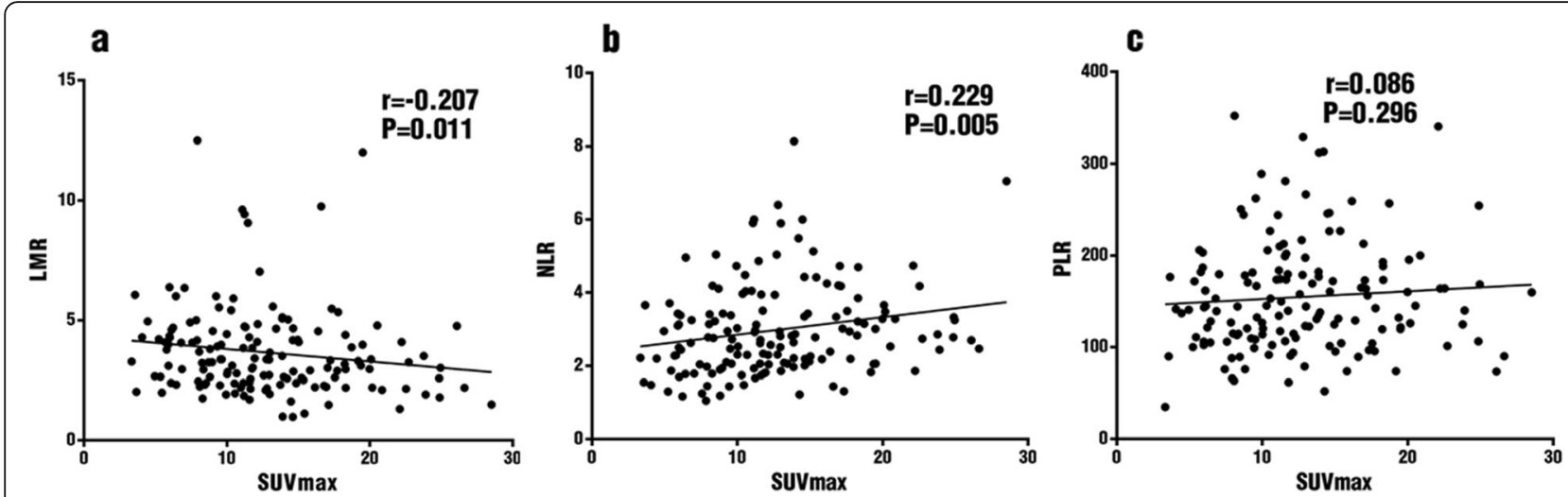

Fig. 1 Correlation between SUVmax and hematological markers LMR $\mathbf{a}, N L R \mathbf{b}$ and PLR $\mathbf{c}$

respectively (Fig. 4a, $p<0.001$ ). Differences in PFS according to the SUV_LMR scores were significant $(0$ vs $1, p<0.001 ; 1$ vs $2, p=0.001 ; 0$ vs $2, p<0.001$ ). Similar results were obtained for OS. The median OS for patients with scores of 0,1 , and 2 was 26.9, 16.4, and 13.0 months, respectively (Fig. $4 \mathrm{~b}, p<0.001$ ). The OS stratifications according to the SUV_LMR scores were also significant ( 0 vs $1, p<0.001 ; 1$ vs $2, p<$ 0.001 ; 0 vs $2, p<0.001$ ).

To further evaluate the prognostic value of the SUV LMR score whilst avoiding the effect of SUVmax and LMR on the SUV_LMR score, another multivariable Cox regression model (Model 2) was constructed. The results demonstrated that the SUV_LMR score was independently associated with PFS $(p<0.001)$ and OS $(p<$ 0.001) (Table 6, Model 2). The patients with a score of 0 exhibited the longest PFS and OS of the subgroups.

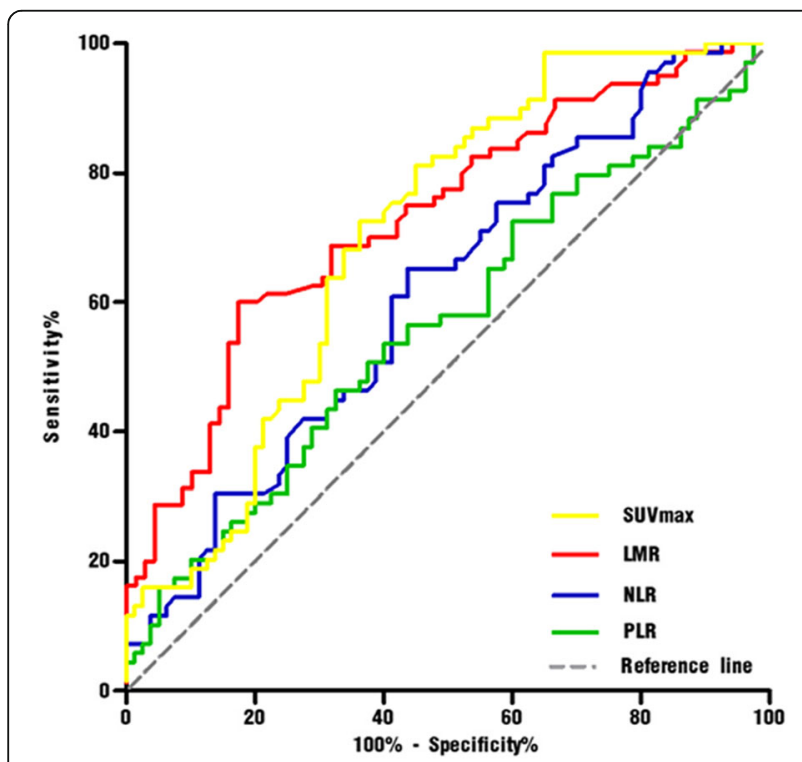

Fig. 2 Receiver operating characteristic curves for SUVmax and hematological markers
Patients with a score of 1 (HR: 2.017; 95\%CI: $1.233-$ $3.300 ; p=0.005$ ) and score of 2 (HR: $3.421 ; 95 \% \mathrm{CI}$ : 1.903-6.148; $\mathrm{p}<0.001)$ exhibited significantly decreased PFS compared with that of patients with a score of 0 . Similarly, patients with a score of 1 (HR: 2.177; 95\%CI: $1.273-3.722 ; p=0.004$ ) and score of 2 (HR: 4.573; 95\% CI: 2.441-8.569; $\mathrm{p}<0.001$ ) also showed significantly worse OS compared with that of patients with a score of 0 .

\section{Discussion}

Our retrospective study revealed that pre-treatment SUVmax and LMR were independent factors for predicting treatment response and prognosis in stage IIIB-IV NSCLC patients receiving chemotherapy. More importantly, an innovative scoring system based on SUVmax and LMR was constructed that can serve as an accurate and effective tool for predicting chemotherapeutic response and prognosis.

SUVmax is one of the most important parameters derived from PET that can accurately measure the metabolic activity of tumors and provide valuable prognostic information. Although the cellular and molecular mechanisms are not well known, some studies have reported that SUVmax is closely associated with biological factors that influence cancer proliferation and progression in NSCLC, such as Ki-67 [27, 28] and VEGF [28]. A large prospective study by Vesselle et al. [27] investigated the correlation between Ki-67 expression and tumor FDG uptake in 178 patients with NSCLC. The results showed that SUVmax was positively correlated with Ki-67 scores in tumor tissue, and it is well known that the overexpression of Ki-67 in tumors indicates active proliferative activity and aggressive biological behaviour. In another study on NSCLC, Takenaka et al. [28] assessed the relationship between SUVmax and intratumoral expression of VEGF and demonstrated that SUVmax was significantly higher in patients with high expression of VEGF, which plays an important role in tumor angiogenesis, 
Table 2 Univariable and multivariable analyses of the first-line response to chemotherapy

\begin{tabular}{|c|c|c|c|c|c|c|c|}
\hline \multirow[t]{2}{*}{ Variables } & \multicolumn{3}{|c|}{ Tumor response } & \multicolumn{2}{|c|}{ Univariable Analysis } & \multicolumn{2}{|c|}{ Multivariable analysis } \\
\hline & $\begin{array}{l}\overline{C R}+ \\
\mathrm{PR}\end{array}$ & $\begin{array}{l}\text { SD+ } \\
\text { PD }\end{array}$ & ORR & OR $(95 \% \mathrm{Cl})$ & $p$ value & OR $(95 \% \mathrm{Cl})$ & $p$ value \\
\hline Age (years) & & & & & $0.042^{*}$ & & 0.251 \\
\hline$\leq 65$ & 57 & 38 & $60.0 \%$ & Ref. & & Ref. & \\
\hline$>65$ & 23 & 31 & $42.6 \%$ & $0.495(0.251-0.974)$ & & $0.593(0.243-1.447)$ & \\
\hline Sex & & & & & 0.177 & & \\
\hline Male & 56 & 55 & $50.5 \%$ & $0.594(0.279-1.266)$ & & & \\
\hline Female & 24 & 14 & $63.2 \%$ & Ref. & & & \\
\hline Smoking & & & & & 0.550 & & \\
\hline Never & 34 & 26 & $56.7 \%$ & Ref. & & & \\
\hline Ever & 46 & 43 & $51.7 \%$ & $0.818(0.423-1.580)$ & & & \\
\hline ECOG PS & & & & & $0.001^{* *}$ & & 0.302 \\
\hline 0 & 49 & 24 & $67.1 \%$ & Ref. & & Ref. & \\
\hline 1 & 31 & 45 & $40.8 \%$ & $0.337(0.173-0.659)$ & & $0.646(0.282-1.481)$ & \\
\hline Lesion type & & & & & 0.344 & & \\
\hline Peripheral & 41 & 30 & $57.7 \%$ & Ref. & & & \\
\hline Central & 39 & 39 & $50.0 \%$ & $0.732(0.383-1.398)$ & & & \\
\hline Histological type & & & & & 0.857 & & \\
\hline Adenocarcinoma & 51 & 43 & $54.3 \%$ & Ref. & & & \\
\hline Squamous & 29 & 26 & $52.7 \%$ & $0.940(0.483-1.832)$ & & & \\
\hline Clinical stage & & & & & $0.004^{* *}$ & & $0.008^{* *}$ \\
\hline 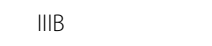 & 46 & 23 & $66.7 \%$ & Ref. & & Ref. & \\
\hline IV & 34 & 46 & $42.5 \%$ & $0.370(0.189-0.721)$ & & $0.283(0.112-0.718)$ & \\
\hline CEA & & & & & $0.042^{*}$ & & 0.170 \\
\hline Normal & 57 & 38 & $60.0 \%$ & Ref. & & Ref. & \\
\hline Increased & 23 & 31 & $42.6 \%$ & $0.495(0.251-0.974)$ & & $0.539(0.223-1.303)$ & \\
\hline Albumin & & & & & 0.093 & & \\
\hline Decreased & 22 & 28 & $44.0 \%$ & $0.555(0.279-1.104)$ & & & \\
\hline Normal & 58 & 41 & $58.6 \%$ & Ref. & & & \\
\hline $\operatorname{WBC}\left(\times 10^{9} / L\right)$ & & & & & $0.003^{* *}$ & & 0.424 \\
\hline$\leq 7.8$ & 53 & 29 & $64.6 \%$ & Ref. & & Ref. & \\
\hline$>7.8$ & 27 & 40 & $40.3 \%$ & $0.369(0.190-0.719)$ & & $0.710(0.307-1.644)$ & \\
\hline LMR & & & & & $<0.001^{* * *}$ & & $<0.001^{* * *}$ \\
\hline$\leq 3.73$ & 32 & 57 & $36.0 \%$ & $0.140(0.065-0.302)$ & & $0.167(0.062-0.454)$ & \\
\hline$>3.73$ & 48 & 12 & $80.0 \%$ & Ref. & & Ref. & \\
\hline NLR & & & & & $0.009^{* *}$ & & 0.737 \\
\hline$\leq 2.67$ & 45 & 24 & $65.2 \%$ & Ref. & & Ref. & \\
\hline$>2.67$ & 35 & 45 & $43.8 \%$ & $0.415(0.214-0.806)$ & & $1.176(0.456-3.032)$ & \\
\hline PLR & & & & & 0.084 & & \\
\hline$\leq 164$ & 54 & 37 & $59.3 \%$ & Ref. & & & \\
\hline$>164$ & 26 & 32 & $44.8 \%$ & $0.557(0.286-1.083)$ & & & \\
\hline SUVmax & & & & & $<0.001^{* * *}$ & & $0.001^{* *}$ \\
\hline$\leq 11.6$ & 50 & 19 & $72.5 \%$ & Ref. & & Ref. & \\
\hline$>11.6$ & 30 & 50 & $37.5 \%$ & $0.228(0.114-0.457)$ & & $0.217(0.090-0.525)$ & \\
\hline
\end{tabular}

ECOG PS Eastern Cooperative Oncology Group Performance Status, CEA carcinoembryonic antigen, WBC white blood cell, $L M R$ lymphocyte-monocyte ratio, NLR neutrophil-lymphocyte ratio, $P L R$ platelet-lymphocyte ratio, SUVmax maximum standardized uptake value, $C R$ complete response, $P R$ partial response, $S D$ stable disease, $P D$ progressive disease, $O R R$ objective response rate, $O R$ odds ratio, $C l$ confidence interval. ${ }^{*}, p<0.05 ;{ }^{* *}, p<0.01 ;{ }^{* * *}, p<0.001$ 


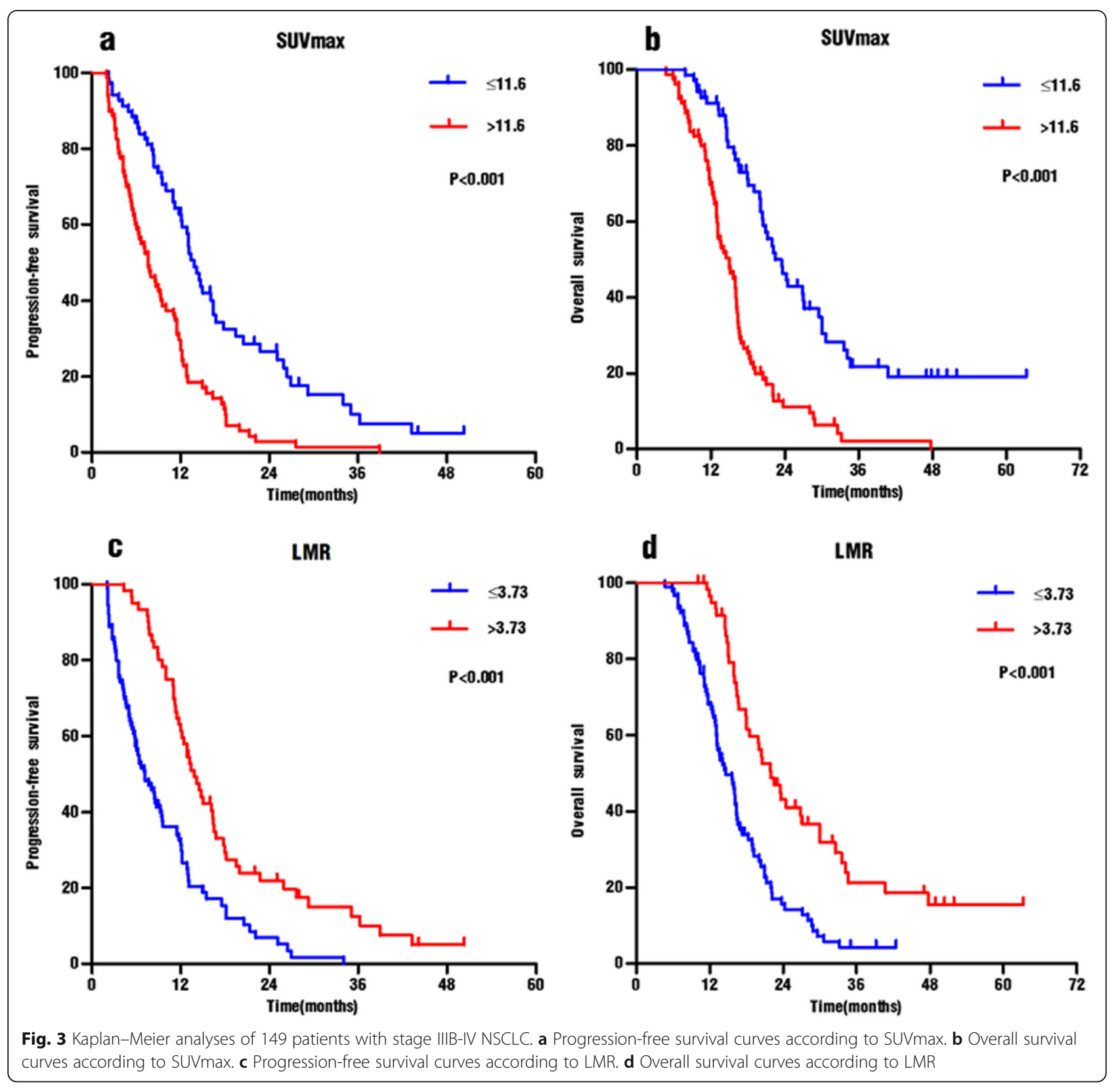

invasion, and metastasis. Above studies revealed that SUVmax could reflect tumor proliferation and angiogenesis, which is related to prognosis. In NSCLC, many studies have demonstrated the prognostic significance of SUVmax [10, 29]. A meta-analysis by Berghmans et al. [29] encompassing 13 studies highlighted tumor SUVmax values as a prognostic factor of NSCLC. In another retrospective study of 315 NSCLC patients, Cerfolio et al. [10] found that patients with SUVmax $\geq 10$ were more likely to have cancer recurrence and shorter survival compared with those of patients with low SUVmax. More importantly, they also concluded that SUVmax was a more powerful independent prognostic factor than TNM stage [10]. Consistent with these findings, we also observed that high SUVmax values (>11.6) of primary tumor is independently associated with poor PFS and OS. In addition, we also demonstrated that a high SUVmax was a significant predictive marker of poor chemotherapeutic response. The mechanism may be related to the overexpression of p53 in tumor cells, as a previous study confirmed the positive correlation between SUVmax and p53 expression [30], and p53 overexpression has been proved to be significantly correlated with chemotherapy resistance in lung cancer [31]. This may 
Table 3 Univariable analyses of PFS and OS

\begin{tabular}{|c|c|c|c|c|c|c|}
\hline \multirow[t]{2}{*}{ Variables } & \multicolumn{3}{|l|}{ PFS } & \multicolumn{3}{|l|}{ os } \\
\hline & $\mathrm{HR}$ & $95 \% \mathrm{Cl}$ & $p$ value & HR & $95 \% \mathrm{Cl}$ & $p$ value \\
\hline Age (years) & & & $0.015^{*}$ & & & $0.008^{* *}$ \\
\hline$\leq 65$ & Ref. & & & Ref. & & \\
\hline$>65$ & 1.567 & $1.093-2.248$ & & 1.666 & $1.142-2.429$ & \\
\hline Sex & & & 0.174 & & & 0.365 \\
\hline Male & 1.320 & $0.885-1.968$ & & 1.216 & $0.796-1.859$ & \\
\hline Female & Ref. & & & Ref. & & \\
\hline Smoking & & & 0.391 & & & 0.717 \\
\hline Never & Ref. & & & Ref. & & \\
\hline Ever & 1.168 & $0.819-1.665$ & & 1.070 & $0.741-1.547$ & \\
\hline ECOG PS & & & $0.007^{* *}$ & & & $0.019^{*}$ \\
\hline 0 & Ref. & & & Ref. & & \\
\hline 1 & 1.610 & $1.136-2.283$ & & 1.548 & $1.073-2.234$ & \\
\hline Lesion type & & & 0.086 & & & 0.443 \\
\hline Peripheral & Ref. & & & Ref. & & \\
\hline Central & 1.357 & $0.958-1.922$ & & 1.152 & $0.802-1.655$ & \\
\hline Histological type & & & 0.835 & & & 0.816 \\
\hline Adenocarcinoma & Ref. & & & Ref. & & \\
\hline Squamous & 1.038 & $0.728-1.482$ & & 0.957 & $0.661-1.386$ & \\
\hline Clinical stage & & & $0.017^{*}$ & & & $0.045^{*}$ \\
\hline$\| \mathrm{II}$ & Ref. & & & Ref. & & \\
\hline IV & 1.529 & $1.078-2.168$ & & 1.450 & $1.008-2.086$ & \\
\hline First-line response & & & $<0.001^{* * *}$ & & & $<0.001^{* * *}$ \\
\hline CR/PR & Ref. & & & Ref. & & \\
\hline $\mathrm{SD} / \mathrm{PD}$ & 2.725 & $1.905-3.898$ & & 2.966 & $2.044-4.306$ & \\
\hline CEA & & & 0.280 & & & 0.719 \\
\hline Normal & 1.219 & $0.851-1.746$ & & 1.071 & $0.737-1.557$ & \\
\hline Increased & Ref. & & & Ref. & & \\
\hline Albumin & & & $0.023^{*}$ & & & 0.140 \\
\hline Decreased & 1.521 & $1.059-2.183$ & & 1.323 & $0.913-1.918$ & \\
\hline Normal & Ref. & & & Ref. & & \\
\hline WBC & & & 0.098 & & & 0.158 \\
\hline$\leq 7.8$ & Ref. & & & Ref. & & \\
\hline$>7.8$ & 1.337 & $0.948-1.887$ & & 1.297 & $0.904-1.860$ & \\
\hline LMR & & & $<0.001^{* * *}$ & & & $<0.001^{* * *}$ \\
\hline$\leq 3.73$ & 2.373 & $1.643-3.429$ & & 2.437 & $1.659-3.579$ & \\
\hline$>3.73$ & Ref. & & & Ref. & & \\
\hline NLR & & & 0.064 & & & 0.067 \\
\hline$\leq 2.67$ & Ref. & & & Ref. & & \\
\hline$>2.67$ & 1.395 & $0.981-1.984$ & & 1.403 & $0.977-2.017$ & \\
\hline PLR & & & 0.107 & & & 0.101 \\
\hline$\leq 164$ & Ref. & & & Ref. & & \\
\hline$>164$ & 1.342 & 0.939-1.918 & & 1.361 & $0.942-1.968$ & \\
\hline SUVmax & & & $<0.001^{* * *}$ & & & $<0.001^{* * *}$ \\
\hline
\end{tabular}


Table 3 Univariable analyses of PFS and OS (Continued)

\begin{tabular}{|c|c|c|c|c|c|c|}
\hline \multirow[t]{2}{*}{ Variables } & \multicolumn{3}{|l|}{ PFS } & \multicolumn{3}{|l|}{ os } \\
\hline & HR & $95 \% \mathrm{Cl}$ & $p$ value & HR & $95 \% \mathrm{Cl}$ & $p$ value \\
\hline$\leq 11.6$ & Ref. & & & Ref. & & \\
\hline$>11.6$ & 2.400 & $1.674-3.440$ & & 2.976 & $2.024-4.375$ & \\
\hline LMR_SUV & & & $<0.001^{* * *}$ & & & $<0.001^{* * *}$ \\
\hline Score 0 & Ref. & & & Ref. & & \\
\hline Score 1 & 2.228 & $1.383-3.590$ & $0.001 * *$ & 2.426 & $1.441-4.085$ & $0.001 * *$ \\
\hline Score 2 & 4.449 & $2.719-7.281$ & $<0.001^{* * *}$ & 5.361 & $3.172-9.058$ & $<0.001^{* * *}$ \\
\hline
\end{tabular}

PFS progression-free survival, OS overall survival, ECOG PS Eastern Cooperative Oncology Group Performance Status, CR complete response, $P R$ partial response, $S D$ stable disease, $P D$ progressive disease, CEA carcinoembryonic antigen, WBC white blood cell, $L M R$ lymphocyte-monocyte ratio, NLR neutrophil-lymphocyte ratio, $P L R$ platelet-lymphocyte ratio, SUVmax maximum standardized uptake value, HR hazard ratio, $C l$ confidence intervals. ${ }^{*}, p<0.05 ;{ }^{* *}, p<0.01 ;{ }^{* * *}, p<0.001$

be an underlying mechanism to explain why the high SUVmax is associated with poor chemotherapeutic effects.

Accumulating evidence has demonstrated that systemic inflammation plays a key role in tumorigenesis, progression and metastasis [17]. LMR, one of the simple markers of systemic inflammatory response, has been shown to correlate with clinical outcomes of NSCLC
$[25,26]$. In a retrospective assessment of 107 patients with advanced lung squamous cell carcinoma who received chemotherapy, Minami et al. showed that a low LMR $(<2.07)$ could independently predict a poor OS, while NLR could not [25]. In terms of short-term efficacy, their results showed that the high LMR group exhibited a higher response rate to chemotherapy than did the low LMR group (25). Lin et al. also reported that

Table 4 Multivariable analyses of PFS and OS (Model 1)

\begin{tabular}{|c|c|c|c|c|c|c|}
\hline \multirow[t]{2}{*}{ Variables } & \multicolumn{3}{|l|}{ PFS } & \multicolumn{3}{|l|}{ OS } \\
\hline & HR & $95 \% \mathrm{Cl}$ & $p$ value & HR & $95 \% \mathrm{Cl}$ & $p$ value \\
\hline Age (years) & & & 0.443 & & & 0.973 \\
\hline$\leq 65$ & Ref. & & & Ref. & & \\
\hline$>65$ & 1.177 & $0.776-1.787$ & & 0.992 & $0.634-1.553$ & \\
\hline ECOG PS & & & 0.443 & & & 0.350 \\
\hline 0 & Ref. & & & Ref. & & \\
\hline 1 & 1.164 & $0.790-1.714$ & & 1.214 & $0.808-1.823$ & \\
\hline Clinical stage & & & $0.003^{* *}$ & & & $0.002^{* *}$ \\
\hline$\| \mathrm{II}$ & Ref. & & & Ref. & & \\
\hline IV & 1.807 & $1.229-2.658$ & & 1.880 & $1.260-2.806$ & \\
\hline First-line response & & & $0.037^{*}$ & & & $0.011^{*}$ \\
\hline CR/PR & Ref. & & & Ref. & & \\
\hline $\mathrm{SD} / \mathrm{PD}$ & 1.572 & $1.027-2.407$ & & 1.799 & $1.143-2.831$ & \\
\hline Albumin & & & 0.089 & & & \\
\hline Decreased & 1.377 & $0.952-1.991$ & & & & \\
\hline Normal & Ref. & & & & & \\
\hline LMR & & & $0.025^{*}$ & & & $0.032^{*}$ \\
\hline$\leq 3.73$ & 1.602 & $1.060-2.420$ & & 1.621 & $1.042-2.521$ & \\
\hline$>3.73$ & Ref. & & & Ref. & & \\
\hline SUVmax & & & $<0.001^{* * *}$ & & & $<0.001^{* * *}$ \\
\hline$\leq 11.6$ & Ref. & & & Ref. & & \\
\hline$>11.6$ & 2.110 & $1.400-3.179$ & & 2.760 & $1.789-4.257$ & \\
\hline
\end{tabular}

PFS progression-free survival, OS overall survival, ECOG PS Eastern Cooperative Oncology Group Performance Status, $C R$ complete response, $P R$ partial response, $S D$ stable disease, $P D$ progressive disease, $L M R$ lymphocyte-monocyte ratio, SUVmax maximum standardized uptake value, $H R$ hazard ratio, $C I$ confidence intervals. ${ }^{*}$, $p<0.05 ;{ }^{* *}, p<0.01 ;{ }^{* * *}, p<0.001$ 
Table 5 Chemotherapeutic response according to LMR_SUV scores

\begin{tabular}{|c|c|c|c|c|c|c|}
\hline SUV_LMR score & $P R+C R$ & $S D+P D$ & ORR & Compared & $p$ value & $p$ value \\
\hline \multirow[t]{2}{*}{ Score $0(n=36)$} & 32 & 4 & $88.9 \%$ & Score 1 & $0.002^{* *}$ & $<0.001^{* * *}$ \\
\hline & & & & Score 2 & $<0.001^{* * *}$ & \\
\hline Score $1(n=57)$ & 34 & 23 & $59.6 \%$ & Score 2 & $<0.001^{* * *}$ & \\
\hline Score $2(n=56)$ & 14 & 42 & $25.0 \%$ & & & \\
\hline
\end{tabular}

SUV standardized uptake value, $L M R$ lymphocyte-monocyte ratio, $C R$ complete response, $P R$ partial response, $S D$ stable disease, $P D$ progressive disease, $O R R$ objective response rate. ${ }^{*}, p<0.05 ;{ }^{* *}, p<0.01 ;{ }^{* * *}, p<0.001$

high LMR values (>4.56) were predictive of a longer PFS and OS in 370 metastatic NSCLC patients receiving chemotherapy [26]. Our data were consistent with these findings, as a low pre-treatment LMR $(\leq 3.73)$ was a significant predictor of unfavourable chemotherapeutic responses and a poor PFS and OS. The exact mechanisms of these associations currently remain unclear, but there are some hypotheses on this issue. On the one hand, it is well known that lymphocytes, especially cytotoxic $\mathrm{T}$ lymphocytes, play a critical role in the antitumor immune response by inducing cytotoxic cell death and suppressing tumor cell proliferation and invasion [32]. A previous study has demonstrated that a low lymphocyte count was associated with a poor DFS in NSCLC patients [33]. On the other hand, circulating monocytes can differentiate into tumor-associated macrophages (TAMs) in the tumor microenvironment, and growing evidence suggests that TAMs promote cancer initiation, progression and metastasis by inducing mutagenesis, stimulating angiogenesis, and suppressing anti-tumor immunity [16-18]. All the above theories suggested that the LMR can reflect the balance between the anti-tumor immunity of the lymphatic system and the unfavourable tumor-promoting effects of monocytes. A low LMR indicates a relatively decreased lymphocyte count and an increased monocyte count, so it may predict a poor clinical outcome.

To summarize, SUVmax represents the local metabolic status of primary tumor, and LMR reflects the host's systemic inflammatory response. The comprehensive evaluation of these two factors may be more accurate and effective at predicting the chemotherapeutic response and prognosis. Interestingly, we demonstrated a weak but significant negative correlation between SUVmax and LMR in this study. A similar correlation between SUVmax and hematological parameters was observed in colorectal cancer [34], NSCLC [35] and breast cancer [36]. In a study of colorectal cancer, Xu et al. [34] demonstrated that SUVmax was significantly correlated with LMR and NLR. In addition, in other studies on NSCLC

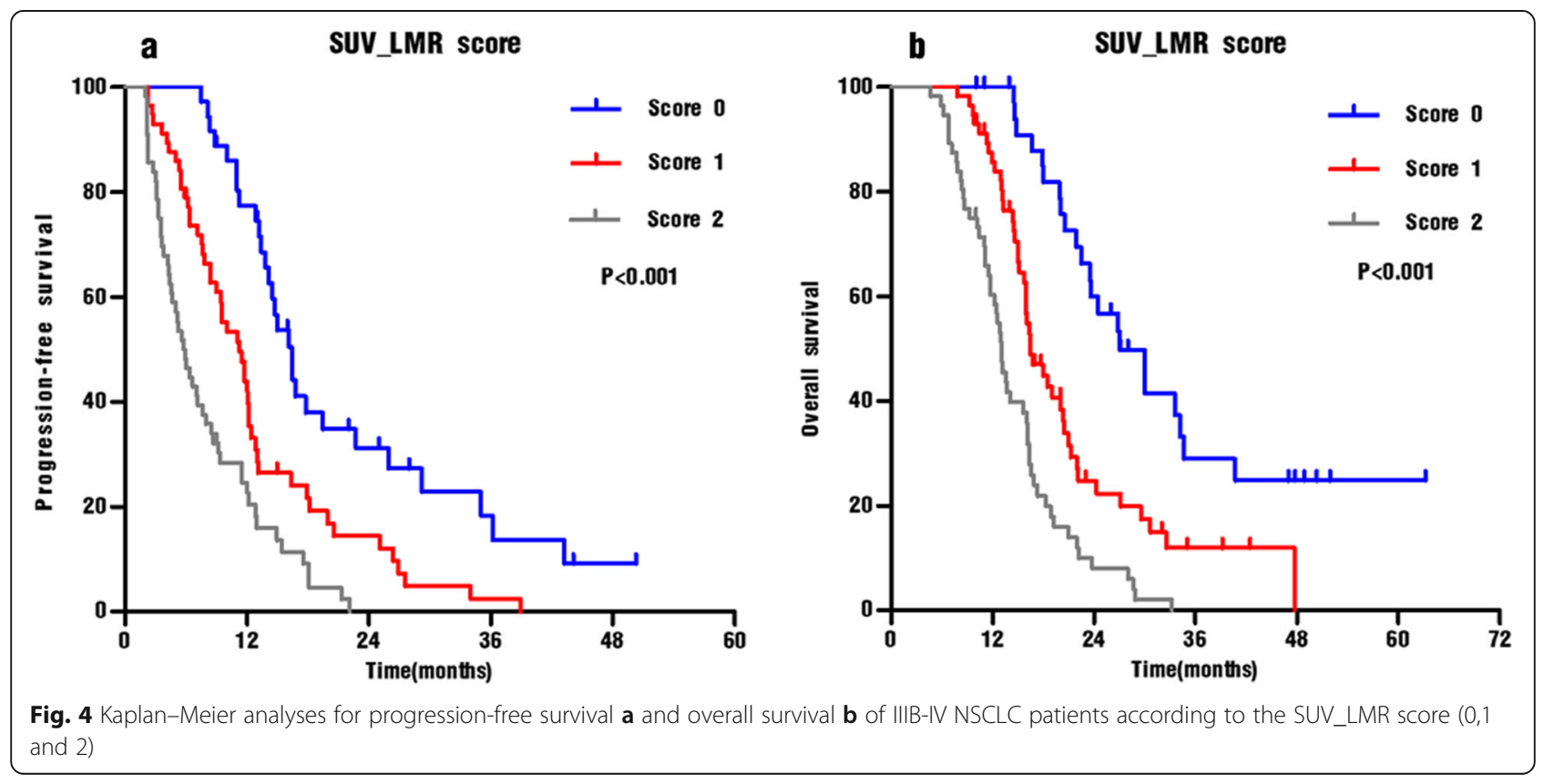


Table 6 Multivariable analyses of PFS and OS (Model 2)

\begin{tabular}{|c|c|c|c|c|c|c|}
\hline \multirow[t]{2}{*}{ Variables } & \multicolumn{3}{|l|}{ PFS } & \multicolumn{3}{|l|}{ OS } \\
\hline & $\overline{\mathrm{HR}}$ & $95 \% \mathrm{Cl}$ & $p$ value & HR & $95 \% \mathrm{Cl}$ & $p$ value \\
\hline Age (years) & & & 0.379 & & & 0.975 \\
\hline$\leq 65$ & Ref. & & & Ref. & & \\
\hline$>65$ & 1.204 & $0.796-1.824$ & & 0.993 & $0.640-1.540$ & \\
\hline ECOG PS & & & 0.487 & & & 0.483 \\
\hline 0 & Ref. & & & Ref. & & \\
\hline 1 & 1.147 & $0.780-1.686$ & & 1.154 & $0.773-1.724$ & \\
\hline Clinical stage & & & $0.004^{* *}$ & & & $0.004^{* *}$ \\
\hline$\| \mathrm{IIB}$ & Ref. & & & Ref. & & \\
\hline IV & 1.752 & $1.190-2.578$ & & 1.802 & $1.207-2.690$ & \\
\hline First-line response & & & $0.035^{*}$ & & & $0.015^{*}$ \\
\hline$C R / P R$ & Ref. & & & Ref. & & \\
\hline $\mathrm{SD} / \mathrm{PD}$ & 1.576 & $1.033-2.406$ & & 1.754 & $1.117-2.753$ & \\
\hline Albumin & & & 0.097 & & & \\
\hline Decreased & 1.367 & $0.945-1.978$ & & & & \\
\hline Normal & Ref. & & & & & \\
\hline LMR_SUV & & & $<0.001^{* * *}$ & & & $<0.001^{* * *}$ \\
\hline Score 0 & Ref. & & & Ref. & & \\
\hline Score 1 & 2.017 & $1.233-3.300$ & $0.005^{* *}$ & 2.177 & $1.273-3.722$ & $0.004^{* *}$ \\
\hline Score 2 & 3.421 & $1.903-6.148$ & $<0.001^{* * *}$ & 4.573 & $2.441-8.569$ & $<0.001^{* * *}$ \\
\hline
\end{tabular}

PFS progression-free survival, OS overall survival, ECOG PS Eastern Cooperative Oncology Group Performance Status, $C R$ complete response, $P R$ partial response, $S D$ stable disease, $P D$ progressive disease, $L M R$ lymphocyte-monocyte ratio, SUVmax maximum standardized uptake value, $H R$ hazard ratio, $C l$ confidence intervals. ${ }^{*}$, $p<0.05 ;{ }^{* *}, p<0.01 ;{ }^{* * *}, p<0.001$

and breast cancer, Jeong et al. [35] and Fujii et al. [36] also demonstrated the correlation between SUVmax and NLR. The results of previous studies may offer some explanations for this correlation. One potential opinion was that inflammatory cells infiltrating the tumor microenvironment, such as neutrophils and macrophages, also consumed FDG, resulting in increased FDG uptake throughout the tumor [37]. Another possible explanation may be related to inflammation-induced angiogenesis. Inflammation promotes hypoxia in the tumor microenvironment and induces angiogenesis by stimulating VEGF secretion [38]. Then, the uptake of FDG will increase significantly during tumor angiogenesis [39]. These analyses shed new insight into the relationship between tumor metabolic activity and the host's inflammatory response process. Therefore, in present study, we established a scoring system based on the SUVmax and LMR, and demonstrated its value to predict PFS and OS, highlighting its prognostic potential. Patients with baseline SUVmax $\leq 11.6$ along with LMR > 3.73 (score 0) exhibited the longest PFS and OS of the three groups, whereas patients with both pre-treatment SUVmax $>11.6$ and LMR $\leq 3.73$ (score 2) showed the worst treatment outcome, with significantly poorer OS and PFS. Another highlight of this study was the association between the SUV_LMR score and first-line chemotherapeutic response. Patients with a score of 0 had the highest ORR among the subgroups, while patients with a score of 2 had the worst ORR. The SUV_LMR score therefore has the potential to predict treatment response and prognosis and may be helpful in selecting appropriate treatment strategies for advanced patients. Patients with a score of 0 appeared to be more sensitive to chemotherapy, so the current platinum-based doublet chemotherapy may be the optimal strategy for them; thus, for these patients, chemotherapy should be implemented as soon as possible. However, for patients with a score of 2 , they seemed to be relatively insensitive to chemotherapy, and their prognosis was extremely poor. Therefore, alternative strategies should be considered for these patients, such as molecularly targeted therapies and immunotherapies.

Some study limitations should be discussed. The study was retrospective and from a single centre, and the number of patients was small. Secondly, selection criteria were limited to stage IIIB-IV NSCLC, and the prognostic impact of the SUV_LMR scores may be differ in those at early disease stages. Finally, the predictive performance 
of the SUV_LMR score needs further validation in larger prospective studies containing more samples.

\section{Conclusions}

Pre-treatment SUVmax and LMR were independent predictive factors of clinical tumor response and prognosis in stage IIIB-IV NSCLC patients who were treated with first-line chemotherapy. More importantly, the SUV LMR score, which is based on primary tumor metabolic activity and the systemic inflammatory response, provides a promising tool to predict chemosensitivity, recurrence and survival of advanced NSCLC.

\section{Abbreviations \\ NSCLC: Non-small cell lung cancer; TNM: Tumor, node, metastasis; FDG-PET/ \\ $\mathrm{CT}$ : Fluorodeoxyglucose positron emission tomography/computed tomography; SUVmax: Maximum standardized uptake value; \\ LMR: Lymphocyte-monocyte ratio; NLR: Neutrophil-lymphocyte ratio; PLR: Platelet- lymphocyte ratio; ECOG PS: Eastern cooperative oncology group performance status; WBC: White blood cell; ORR: Objective response rates; CR: Complete response; PR: Partial response; SD: Stable disease; PD: Progressive disease; OS: Overall survival; PFS: Progression-free survival; ROC: Receiver-operating characteristic; AUC: Area under the curves; VEGF: Vascular endothelial growth factor}

\section{Acknowledgements}

Not applicable.

\section{Authors' contributions}

YPS and MHL planned and designed the study. CSW collected patients' information. CSW and FS performed statistical analysis. KWZ and CSW wrote the manuscript. LM and YH helped perform the analysis with constructive discussions. All authors have been involved in drafting the manuscript or revising it critically for important intellectual content and approved the final manuscript. The authors read and approved the final manuscript.

\section{Funding}

Not applicable.

\section{Availability of data and materials}

The datasets used and/or analysed during the current study are available from the corresponding author on reasonable request.

\section{Ethics approval and consent to participate}

The ethics committee of Shandong Cancer Hospital and Institute approved the study. Also, administrative permissions to access the patients' clinical data used in our research were granted by the ethical review board. And written informed consent was waived because of its retrospective design.

\section{Consent for publication}

Not applicable.

\section{Competing interests}

The authors declare that they have no competing interests.

\footnotetext{
Author details

1Department of Radiation Oncology, Yantai Yuhuangding Hospital, 20 Yudong Road, Yantai 264000, Shandong, People's Republic of China. ${ }^{2}$ Department of Radiation Oncology, Shandong Cancer Hospital and Institute, Shandong University, 440 Jiyan Road, Jinan 250117, Shandong, People's Republic of China. ${ }^{3}$ Department of Nuclear Medicine, Shandong Cancer Hospital and Institute, Shandong University, 440 Jiyan Road, Jinan 250117, Shandong, People's Republic of China.
}

Received: 20 July 2020 Accepted: 2 January 2021

Published online: 14 January 2021

\section{References}

1. Siegel RL, Miller KD, Jemal A. Cancer statistics, 2018. CA Cancer J Clin. 2018; 68:7-30.

2. Molina J, Yang P, Cassivi S, Schild S, Adjei A. Non-small cell lung cancer: epidemiology, risk factors, treatment, and survivorship. Mayo Clin Proc. 2008:83:584-94.

3. Goldstraw P, Ball D, Jett JR, Le Chevalier T, Lim E, Nicholson AG, et al. Nonsmall-cell lung cancer. Lancet. 2011;378:1727-40.

4. Shanafelt TD, Loprinzi C, Marks R, Novotny P, Sloan J. Are chemotherapy response rates related to treatment-induced survival prolongations in patients with advanced cancer? J Clin Oncol. 2004;22:1966-74.

5. Shepherd F, Crowley J, Van Houtte P, Postmus P, Carney D, Chansky K, et al. The International Association for the Study of Lung Cancer lung cancer staging project: proposals regarding the clinical staging of small cell lung cancer in the forthcoming (seventh) edition of the tumor, node, metastasis classification for lung cancer. J Thorac Oncol. 2007;2:1067-77.

6. Tanoue LT. Staging of non-small cell lung cancer. Semin Respir Crit Care Med. 2008;29:248-60.

7. Hanahan D, Weinberg RA. Hallmarks of cancer: the next generation. Cell. 2011;144:646-74.

8. Grootjans W, de Geus-Oei L-F, Troost EGC, Visser EP, Oyen WJG, Bussink J. PET in the management of locally advanced and metastatic NSCLC. Nat Rev Clin Oncol. 2015;12:395-407.

9. Berghmans T, Dusart M, Paesmans M, Hossein-Foucher C, Buvat I, Castaigne C, et al. Primary tumor standardized uptake value (SUVmax) measured on fluorodeoxyglucose positron emission tomography (FDG-PET) is of prognostic value for survival in non-small cell lung cancer (NSCLC): a systematic review and meta-analysis (MA) by the European lung Cancer working party for the IASLC lung Cancer staging project. J Thorac Oncol. 2008:3:6-12

10. Cerfolio RJ, Bryant AS, Ohja B, Bartolucci AA. The maximum standardized uptake values on positron emission tomography of a non-small cell lung cancer predict stage, recurrence, and survival. J Thorac Cardiovasc Surg. 2005:130:151-9.

11. Downey RJ, Akhurst T, Gonen M, Vincent A, Bains MS, Larson S, et al. Preoperative F-18 fluorodeoxyglucose-positron emission tomography maximal standardized uptake value predicts survival after lung cancer resection. J Clin Oncol. 2004:22:3255-60.

12. Sasaki R, Komaki R, Macapinlac H, Erasmus J, Allen P, Forster $K$, et al. [18F]fluorodeoxyglucose uptake by positron emission tomography predicts outcome of non-small-cell lung cancer. J Clin Oncol. 2005;23:1136-43.

13. Bille A, Okiror L, Skanjeti A, Errico L, Arena V, Penna D, et al. The prognostic significance of maximum standardized uptake value of primary tumor in surgically treated non-small-cell lung cancer patients: analysis of 413 cases. Clin Lung Cancer. 2013;14:149-56.

14. Agarwal M, Brahmanday G, Bajaj SK, Ravikrishnan KP, Wong CY. Revisiting the prognostic value of preoperative 18F-fluoro-2-deoxyglucose (18F-FDG) positron emission tomography (PET) in early-stage (I \& II) non-small cell lung cancers (NSCLC). Eur J Nucl Med Mol Imaging. 2010;37:691-8.

15. Hoang JK, Hoagland LF, Coleman RE, Coan AD, Herndon JE 2nd, Patz EF Jr. Prognostic value of fluorine-18 fluorodeoxyglucose positron emission tomography imaging in patients with advanced-stage non-small-cell lung carcinoma. J Clin Oncol. 2008;26:1459-64.

16. DeNardo DG, Andreu P, Coussens LM. Interactions between lymphocytes and myeloid cells regulate pro- versus anti-tumor immunity. Cancer Metastasis Rev. 2010;29:309-16.

17. Grivennikov SI, Greten FR, Karin M. Immunity, inflammation, and cancer. Cell. 2010;140:883-99.

18. Qian BZ, Pollard JW. Macrophage diversity enhances tumor progression and metastasis. Cell. 2010;141:39-51.

19. Sun $Y$, Zhang $L$. The clinical use of pretreatment $N L R, P L R$, and $L M R$ in patients with esophageal squamous cell carcinoma: evidence from a metaanalysis. Cancer Manag Res. 2018;10:6167-79.

20. Chan JC, Chan DL, Diakos Cl, Engel A, Pavlakis N, Gill A, et al. The lymphocyte-to-monocyte ratio is a superior predictor of overall survival in comparison to established biomarkers of Resectable colorectal Cancer. Ann Surg. 2017;265:539-46 
21. Marin Hernandez C, Pinero Madrona A, Gil Vazquez PJ, Galindo Fernandez PJ, Ruiz Merino G, Alonso Romero JL, et al. Usefulness of lymphocyte-tomonocyte, neutrophil-to-monocyte and neutrophil-to-lymphocyte ratios as prognostic markers in breast cancer patients treated with neoadjuvant chemotherapy. Clin Transl Oncol. 2018;20:476-83.

22. Wang $Y, H u X, X u$ W, Wang H, Huang Y, Che G. Prognostic value of a novel scoring system using inflammatory response biomarkers in non-small cell lung cancer: a retrospective study. Thorac Cancer. 2019;10:1402-11.

23. Chen $Y$, Wang W, Zhang $X, Y u X, X i K$, Wen $Y$, et al. Prognostic significance of combined preoperative platelet-to-lymphocyte ratio and lymphocyte-tomonocyte ratio in patients undergoing surgery with stage IB non-small-cell lung cancer. Cancer Manag Res. 2018;10:5411-22.

24. Guo M, Li W, Li B, Zou B, Wang S, Meng X, et al. Prognostic value of delta inflammatory biomarker-based nomograms in patients with inoperable locally advanced NSCLC. Int Immunopharmacol. 2019;72:395-401.

25. Minami S, Ihara S, Komuta K. Pretreatment lymphocyte to monocyte ratio as a prognostic marker for advanced pulmonary squamous cell carcinoma treated with chemotherapy. J Clin Med Res. 2018;10:657-64.

26. Lin GN, Peng JW, Xiao JJ, Liu DY, Xia ZJ. Prognostic impact of circulating monocytes and lymphocyte-to-monocyte ratio on previously untreated metastatic non-small cell lung cancer patients receiving platinum-based doublet. Med Oncol. 2014:31:70.

27. Vesselle H, Salskov A, Turcotte E, Wiens L, Schmidt R, Jordan C, et al. Relationship between non-small cell lung cancer FDG uptake at PET, tumor histology, and Ki-67 proliferation index. J Thorac Oncol. 2008;3:971-8.

28. Takenaka T, Yano T, Ito K, Morodomi Y, Miura N, Kawano D, et al. Biological significance of the maximum standardized uptake values on positron emission tomography in non-small cell lung cancer. J Surg Oncol. 2009;100: 688-92.

29. Lepage C, Rachet B, Jooste V, Faivre J, Coleman MP. Continuing rapid increase in esophageal adenocarcinoma in England and Wales. Am J Gastroenterol. 2008;103:2694-9.

30. Bai L, Guo C, Wang J, Liu X, Li Y, Li M, et al. 18F-fludrodeoxyglucose maximal standardized uptake value and metabolic tumor burden are associated with major chemotherapy-related tumor markers in NSCLC patients. Onco Targets Ther. 2016;9:6315-24.

31. Breen L, Heenan M, Amberger-Murphy V, Clynes M. Investigation of the role of p53 in chemotherapy resistance of lung cancer cell lines. Anticancer Res. 2007:27:1361-4.

32. Hung K, Hayashi R, Lafond-Walker A, Lowenstein C, Pardoll D, Levitsky H. The Central Role of CD4+ T Cells in the Antitumor Immune Response. J Exp Med. 1998;188:2357-68.

33. Zhang J, Huang SH, Li H, Li Y, Chen XL, Zhang WQ, et al. Preoperative lymphocyte count is a favorable prognostic factor of disease-free survival in non-small-cell lung cancer. Med Oncol. 2013;30:352.

34. Xu J, Li Y, Hu S, Lu L, Gao Z, Yuan H. The significant value of predicting prognosis in patients with colorectal cancer using (18)F-FDG PET metabolic parameters of primary tumors and hematological parameters. Ann Nucl Med. 2019:33:32-8.

35. Jeong E, Hyun SH, Moon SH, Cho YS, Kim B-T, Lee K-H. Relation between tumor FDG uptake and hematologic prognostic indicators in stage I lung cancer patients following curative resection. Medicine. 2017;96:e5935.

36. Fujii T, Yanai K, Tokuda S, Nakazawa Y, Kurozumi S, Obayashi S, et al. Relationship between FDG uptake and neutrophil/lymphocyte ratio in patients with invasive ductal breast Cancer. Anticancer Res. 2018;38:4927-31.

37. Kubota R, Yamada S, Kubota K, Ishiwata K, Tamahashi N, Ido T. Intratumoral distribution of fluorine-18-fluorodeoxyglucose in vivo: high accumulation in macrophages and granulation tissues studied by microautoradiography. J Nucl Med. 1992;33:1972-80.

38. Kwilas A, Donahue R, Tsang K, Hodge J. Immune consequences of tyrosine kinase inhibitors that synergize with Cancer immunotherapy. Cancer Cell Microenviron. 2015;2:e677.

39. Kurdziel K, Lindenberg L, Choyke P. Oncologic angiogenesis imaging in the clinic: how and why? Imaging Med. 2011;3:445-57.

\section{Publisher's Note}

Springer Nature remains neutral with regard to jurisdictional claims in published maps and institutional affiliations.

\section{Ready to submit your research? Choose BMC and benefit from:}

- fast, convenient online submission

- thorough peer review by experienced researchers in your field

- rapid publication on acceptance

- support for research data, including large and complex data types

- gold Open Access which fosters wider collaboration and increased citations

- maximum visibility for your research: over $100 \mathrm{M}$ website views per year

At BMC, research is always in progress.

Learn more biomedcentral.com/submissions 